\title{
Reliability Modeling and Performance Analysis of Dumper Systems in Mining by KME Method
}

\author{
Chandra Mouli ${ }^{\dot{A}^{*}}$, Subbarao Chamarthi ${ }^{\dot{\AA}}$, Ravi Chandra $\mathrm{G}^{\dot{\mathrm{A}}}$ and Anil Kumar $\mathrm{V}^{\dot{\mathrm{A}}}$ \\ ${ }^{\dot{A}}$ Mechanical Engineering Department, Vardhaman college of engineering, Andhrapradesh, India \\ Accepted 10 January 2014, Available online 01 February 2014, Special Issue-2, (February 2014)
}

\begin{abstract}
Dumper is now used as a loading machine for intermediate mechanization in underground coal mining. For survival in the intense competition in the global business environment in recent years it is essential that LHD machine should be reliable and maintained effectively and efficiently. This paper seeks to study the reliability, availability and maintainability (RAM) of an 36T dumper machine with failure and repair data by KME method. The constraints and reasons for machine unavailability are outlined. The reliability and maintainability of an LHD and its subsystems are evaluated. Reliability and maintainability of an LHD system are disappointing. There is room to take decisions on optimal maintenance planning and machine improvement from this analysis.
\end{abstract}

Keywords: reliability, availability, maintainability, LHD, KME.

\section{Introduction}

Man has been constantly on the outlook of better working of Machines right from the invention of wheel till the sophisticated machinery of today. The machine life is most important in any production unit, as the machines are backbone of an industry. The need for not only efficient, but also reliable maintenance of the machinery is realized. The reliability of machinery is essential particularly, in production process, such as mines and heavy machinery, since the breakdown of any machine would cause an unpredictable loss or damage. Therefore, it is obvious that the reliability of such machine would have considerable impact not only on production but also machine life and human life.

Prevention is better than cure. Instead of allowing the occurrence of failure and suffering from huge loss or damage of assets, lives and environment, it is always worthwhile forestalling the occurrence. For such a fearless environment of successful operations without any failures, the machines must be maintained to exhibit high reliability. Thus it is an urgent need to apply the reliability centered maintenance techniques rather than time based and failure based maintenance techniques. The maintenance planning of equipment hence requires the orientation of reliability at every stage of its life. The present study is on effort in this direction that can provide some guidelines while planning the maintenance activities with an orientation of reliability.

There is a wide scope for conducting the analysis on the dumpers at OCP-III of Ramagundam. These machines are about 12 to 15 years old and have approximately run

*Corresponding author: Chandra Mouli for about 95,000 machine hours on an average. This enables to take up these machines for study as they are suspected to have reached the third stage of bathtub curve (Machine Life Cycle).

There are several testing methods available for testing the behavior of these machines. The Trend analysis, Total Time Test (TTT) plotting are some effective tools to mention. The TTT plotting can be done using various statistical tools such as Most Likely Estimates (MLE), Kaplan-Meir Estimation (KME) and Piecewise Exponential Estimation (PEXE) etc. The present project is carried out with KME. The results are confirmed by the other methods namely MLE and PEXE. Further the Kaplan-Meir estimator is made used to find the design life, optimal maintenance period etc, which are useful information in maintenance planning. And there is further scope to extend this project by preparing suitable software so as to achieve the better and effective Reliability Centered Maintenance Planning.

\section{Procedure for RCM Modelling}

The field data is collected for the equipment categorized under repaired items in the form of Time between Failures (TBFs) and Time To Repair (TTRs). The data inconsistencies and errors are removed and the refined data is analyzed by both types of models viz. graphical and analytical models. However, more importance is given to graphical method since it provides better simple understanding and can be easily reproduced. The graphical tests such as eye-ball analysis, cumulative plot test and serial correlation determine the presence of trend. The machines, which exhibit presence of strong trend, are 
Table 1 Cumulative plot test table-C-374

\begin{tabular}{|l|l|l|l|l|l|}
\hline Failure Number & TTR & CTTR & Cause & TBF & CTBF \\
\hline 1 & 8 & 8 & Steering Problem & 1776 & 1776 \\
\hline 2 & 192 & 200 & Accident & 144 & 1920 \\
\hline 3 & 12 & 212 & Suspension Problem & 1920 & 3840 \\
\hline 4 & 72 & 284 & Bucket Welding & 504 & 4344 \\
\hline 5 & 18 & 302 & Operator Seat Damaged & 120 & 4464 \\
\hline 6 & 16 & 318 & Hydraulic Hose Problem & 1176 & 5640 \\
\hline 7 & 24 & 342 & Trans Problem & 768 & 6408 \\
\hline 8 & 8 & 350 & Radiator Problem & 24 & 6432 \\
\hline 9 & 8 & 358 & CLS & 264 & 6696 \\
\hline 10 & 8 & 366 & Bucket Welding & 336 & 7032 \\
\hline 11 & 32 & 398 & Bucket Damaged & 48 & 7080 \\
\hline 12 & 48 & 446 & Exhaust Problem & 2160 & 9240 \\
\hline 13 & 16 & 462 & Oil Leakage & 1896 & 11136 \\
\hline 14 & 96 & 558 & NTL & 3480 & 14616 \\
\hline 15 & 48 & 606 & Engine oil Leak & & 14616 \\
\hline
\end{tabular}

Table 2 KME Method Table for C-374

\begin{tabular}{|l|l|l|l|l|l|l|l|}
\hline F.NO & OTBF & LN(OTBF) & TI(BEETA) & PRODUCT & CDF & PHI & SLOPE \\
\hline 1 & 24 & 3.178054 & 210.7541 & 669.788 & 0.001222 & 0.000252 & 0.001725 \\
\hline 2 & 48 & 3.871201 & 677.0202 & 2620.881 & 0.00392 & 0.000765 & 0.005449 \\
\hline 3 & 120 & 4.787492 & 3166.566 & 15159.91 & 0.018203 & 0.008231 & 0.034665 \\
\hline 4 & 144 & 4.969813 & 4304.286 & 21391.5 & 0.024662 & 0.009254 & 0.04317 \\
\hline 5 & 264 & 5.575949 & 11942.75 & 66592.17 & 0.066941 & 0.039391 & 0.145722 \\
\hline 6 & 336 & 5.817111 & 17924.24 & 104267.3 & 0.098764 & 0.051489 & 0.201742 \\
\hline 7 & 504 & 6.222576 & 35474.37 & 220742 & 0.186009 & 0.119207 & 0.424423 \\
\hline 8 & 768 & 6.64379 & 72094.78 & 478982.5 & 0.341809 & 0.282092 & 0.905993 \\
\hline 9 & 1176 & 7.069874 & 147725.2 & 1044398 & 0.575581 & 0.596851 & 1.769282 \\
\hline 10 & 1776 & 7.482119 & 295723.4 & 2212637 & 0.820153 & 0.984265 & 2.788684 \\
\hline 11 & 1896 & 7.547502 & 330136.2 & 2491704 & 0.852702 & 0.991999 & 2.8367 \\
\hline 12 & 1920 & 7.56008 & 337202.4 & 2549278 & 0.858618 & 0.992186 & 2.842991 \\
\hline 13 & 2160 & 7.677864 & 411162.1 & 3156846 & 0.907945 & 1 & 2.907945 \\
\hline 14 & 3480 & 8.154788 & 917777.5 & 7484280 & 0.995129 & 1 & 2.995129 \\
\hline & & 86.55821 & 2585522 & 19849570 & & & \\
\hline
\end{tabular}

Table 3 Cumulative plot test table-CD-313

\begin{tabular}{|l|l|l|l|l|l|}
\hline Failure Number & TTR & CTTR & Cause & HRS & CTBF \\
\hline 1 & 16 & 16 & OITDS & 432 & 432 \\
\hline 2 & 8 & 24 & Periodical Maintenance & 2784 & 3216 \\
\hline 3 & 4 & 28 & Air Leak & 456 & 3672 \\
\hline 4 & 18 & 46 & SOS & 408 & 4080 \\
\hline 5 & 12 & 58 & Ari Filter Cleaned & 2328 & 6408 \\
\hline 6 & 36 & 94 & Suspension & 3192 & 9600 \\
\hline 7 & 8 & 102 & Brake & 6 & 9606 \\
\hline 8 & 16 & 118 & Brake & 168 & 9774 \\
\hline 9 & 12 & 130 & Oil leak & 840 & 10614 \\
\hline 10 & 8 & 138 & Machine topped & 216 & 10830 \\
\hline
\end{tabular}

Table 4 KME Method Table for CD-313

\begin{tabular}{|l|l|l|l|l|l|l|l|}
\hline F.NO & OTBF & LN(OTBF $)$ & TI(BEETA) & PRODUCT & CDF & PHI & SLOPE \\
\hline 1 & 6 & 1.791759 & 19.93024 & 35.7102 & 0.000139 & $3.6849 \mathrm{E}-06$ & 0.000147 \\
\hline 2 & 168 & 5.123964 & 5203.152 & 26660.76 & 0.035685 & 0.02259044 & 0.080866 \\
\hline 3 & 216 & 5.375278 & 7916.583 & 42553.84 & 0.053786 & 0.02557248 & 0.104931 \\
\hline 4 & 408 & 6.011267 & 22898.26 & 137647.6 & 0.147783 & 0.07866419 & 0.305111 \\
\hline 5 & 432 & 6.068426 & 25191.72 & 152874.1 & 0.161324 & 0.07946089 & 0.320246 \\
\hline 6 & 456 & 6.122493 & 27572.19 & 168810.5 & 0.175151 & 0.08011173 & 0.335375 \\
\hline
\end{tabular}




\begin{tabular}{|l|l|l|l|l|l|l|l|}
\hline 7 & 840 & 6.733402 & 76479.74 & 514968.8 & 0.413809 & 0.21491177 & 0.843633 \\
\hline 8 & 2328 & 7.752765 & 419625.2 & 3253256 & 0.946631 & 0.99236955 & 2.93137 \\
\hline 9 & 2784 & 7.931644 & 565714.9 & 4487049 & 0.98076 & 1 & 2.98076 \\
\hline 10 & 3192 & 8.068403 & 710861.5 & 5735517 & 0.993018 & 1 & 2.993018 \\
\hline & & 60.9794 & 1861483 & 14519373 & & & \\
\hline
\end{tabular}

further analyzed and fitted into non-homogeneous Poisson process (NHPP) model. Power law process (PLP) model, one of the most popular and commonly used NHPP models can be used for such study.

If there is no trend, it confirms the independently and identically distributed (i.i.d.) assumption. The values obtained can be checked with some analytical tests such as Laplace test. The machines free from trend are further graphically analyzed through total time on test (TTT) plots. The exponential fit that confirms homogeneous Poisson process (HPP) models can be known from this analysis, otherwise can be categorized as renewable process (RP) model which is in accordance with Weibull pattern. The goodness of fit (analytical) tests can confirm this. . Thus, reliability characteristics and maintenance schedules can be estimated. Further, their reliability growth plots can also be drawn to estimate the improvements. Algorithmically, it is explained as given below and followed by a flow chart in Figure.

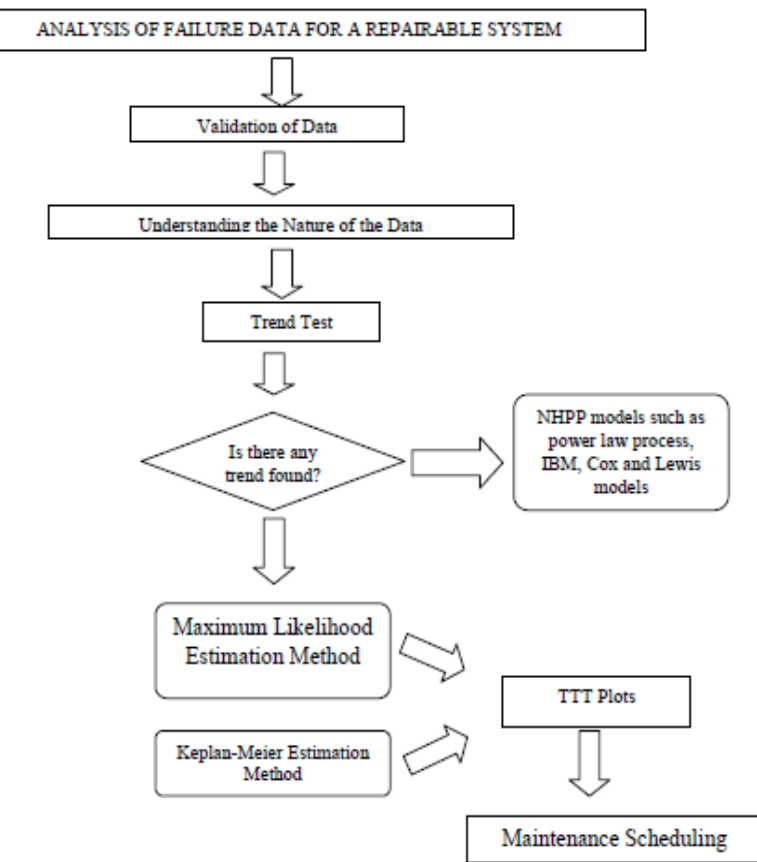

Fig.1 Flow chart of Method for Reliability Analysis

\section{Results and discussion}

As expected the dumpers operated at OCP-III, SCCL, Ramagundam are exhibiting high failure rate and low availability than other equipment. A systematic procedure/approach is established applying the relevant models available in literature on the field data collected to analyze the identified problem. After Ploting the graphs by the data colleceted for the dumpers C-374 and CD-313.
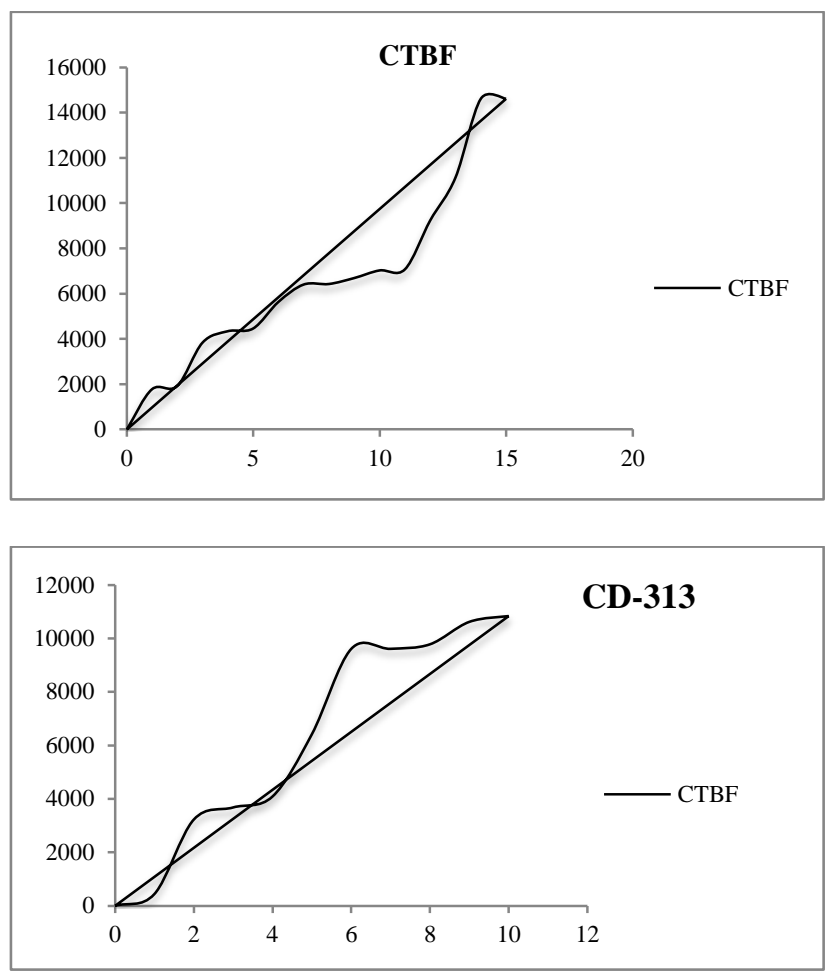

Fig.2 Graphs of cumulative plot test (Failure No Vs Cumulative Time between Failures)
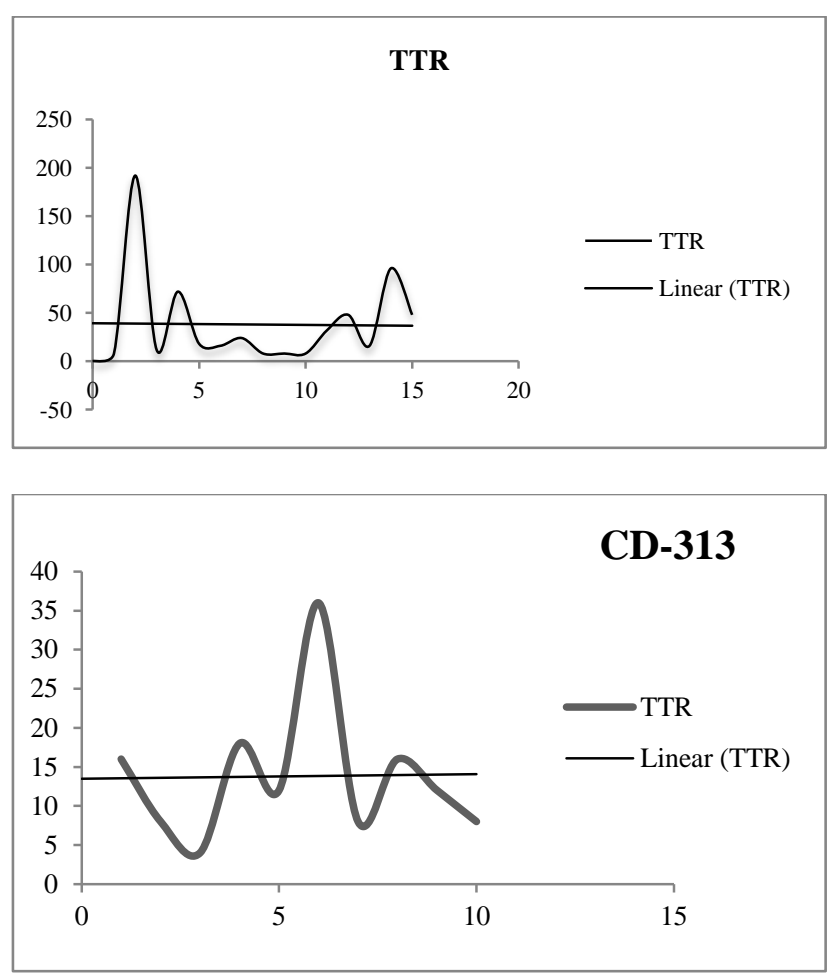

Fig.3 Graphs of eye-ball test (Failure No Vs Time Taken for Repair)

257 | International Conference on Advances in Mechanical Sciences 2014 
Table 5 Trend Analysis for dumpers C-374 \& CD-313

\begin{tabular}{|l|l|l|l|l|}
\hline S.No & Dumper No & Cumulative Trend Test & Eye Ball Trend Test & Trend \\
\hline 1 & C-374 & Weak +Ve Trend & No Trend & No Trend \\
\hline 2 & CD-313 & No Trend & No Trend & No Trend \\
\hline
\end{tabular}
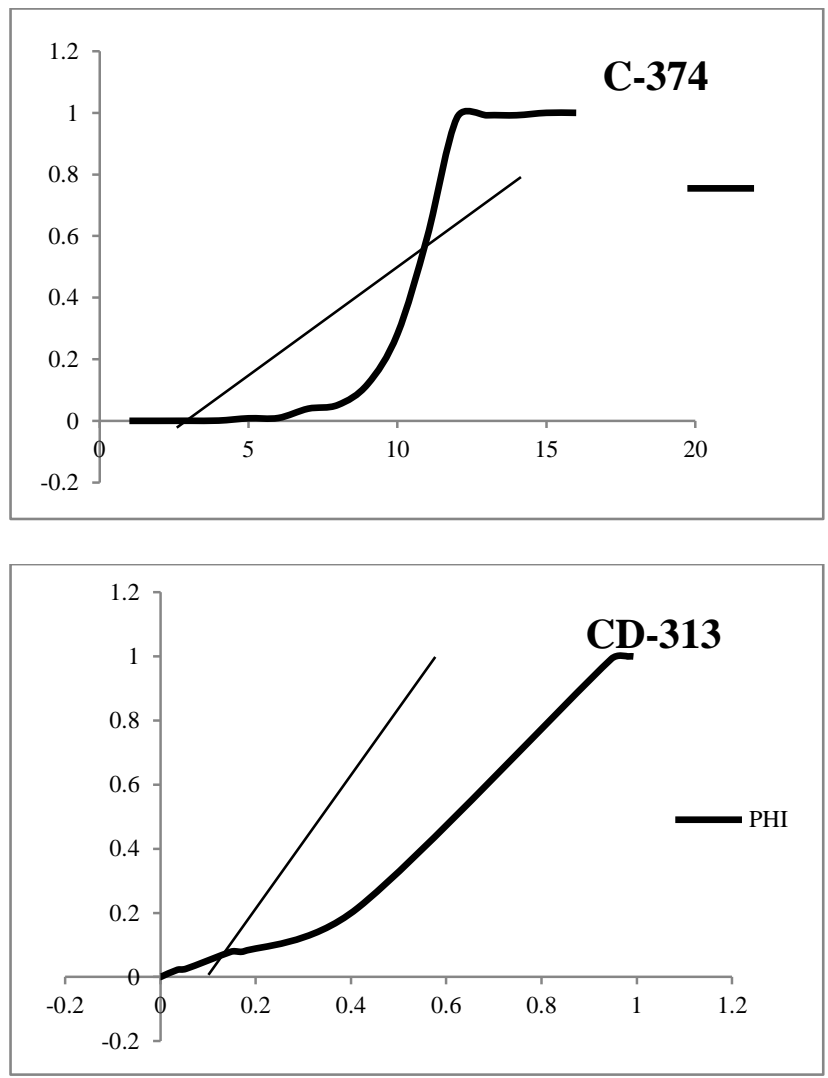

Fig.4 Graphs of Kaplan Meier Estimation (KME) Method (CDF Vs PHI)

The trend analysis shows that the two dumpers are showing no trend.The KME method has proven that both the dumpers are detoriating.

\section{Conclusion}

The present study is confined to a small no. of equipment i.e. 36T trucks. Data collection is not only time consuming and proper collection is possible only when the men concerned maintain proper log of failure/ repair reports is a systematic organized way. Equipment performance depends among other things than its age also. Failure/repair data, properly collected analyzed and stored can be used by the management for a(a) maintenance planning, (b) spare parts provision and (c) ordering new equipment depending upon the life of the project. Right now, cost of maintenance, equipment wise is not readily available for evaluation of effectiveness of maintenance. There is a need to provide a PC at the mine workshops to $\log$ the information and store for retrieval. The log sheets should properly be planned and reporting system has to be perfected. It is observed that there is vast scope for improving machine utilized hours in case of $85 \mathrm{~T}$ dumpers by reducing the idle hours by properly reorganizing the

interfacing activities and maintenance plans. Performance of mine not only depends upon production equipment like shovels/dumpers but very much effected by availability and utilization of service equipment like dozers, scrapers, graders and other equipment. An integrated study of availability of all the equipment in a mine can only improve the productivity through enhanced utilization of production equipment in spite of their availability.

\section{References}

B Samanta, (2000). Challenge and strategies for performance improvement of a large public sector coal company in the face of changing business scenario in India. Unpublished MBA. project, , IGNOU, New Delhi, India.

B Samanta,., Sarkar, B., and S.K. Mukherjee(2001), An application of Weibull distribution for reliability study of shovel machine used in a coal mine. MGMI, Transactions, vol. 97, nos. 1 and 2, , pp. 77-86.

U Kumar,., Klefsjo, B., and Granholm, S. (1989) Reliability investigation for a fleet of load haul dump machines in a Swedish mine. Reliability Engineering and System Safety, vol. 26, , pp. 341-361.

J paraszczak,. and Perreault, F. (1994) Reliability of diesel powered load-hauldumpmachines in an underground Quebec mine. CIM Bulletin, vol. 87,no. 978, , pp. 123-127

J Maiti,. and Dasgupta, S. (2001) Reliability modelling of repairable systems - an application of NHPP model to LHD machine. Proc. on Underground Mine Mechanization, ISM, Dhanbad, India, , pp. 212-220.

U Kumar,. and Huang, Y. 1993 The application of Markov chain for studying the operational reliability of the production system at KIRUNA mine. In Safety and Reliability Assessment-an integral approach. Kafka, P. and Wolf, J.(eds). Elsevier Science Publications., pp. 629-636. 